\title{
Erratum to: Genesis of Paleocene and Lower Eocene shallow-water nodular limestone of South Tibet (China)
}

\author{
Michaela M. Kahsnitz ${ }^{1}$ - Helmut Willems ${ }^{1,2}$
}

Published online: 18 August 2017

(C) Springer-Verlag GmbH Germany 2017

\section{Erratum to: Carbonates Evaporites DOI 10.1007/s13146-017-0360-7}

Unfortunately, formation layer thicknesses in the Abstract and Introduction were incorrectly published in the original version and they are corrected by this Erratum.

In the Abstract section, second paragraph should read as: "The negative carbon isotope excursion representative for the Paleocene-Eocene boundary is located in one nodular limestone bed of the Zhepure Shan Formation showing an extraordinary thickness of about $11 \mathrm{~m}$, inspiring the question under which conditions these nodular limestones were formed."

In the Introduction section third paragraph should read as: "The extraordinary thickness of about $11 \mathrm{~m}$ of this isotope excursion at Tingri, compared to the CIE from ODP690 (about $1 \mathrm{~m}$ ) described by Bains et al. (1999), requires thorough investigations to determine under which conditions these nodular limestones were formed.

The online version of the original article can be found under doi:10.1007/s13146-017-0360-7.

Michaela M. Kahsnitz

michaela.kahsnitz@uni-bremen.de

1 Department of Geosciences, University of Bremen, 28359 Bremen, Germany

2 Nanjing Institute of Geology and Paleontology, Chinese Academy of Sciences, Nanjing 210008, China 